
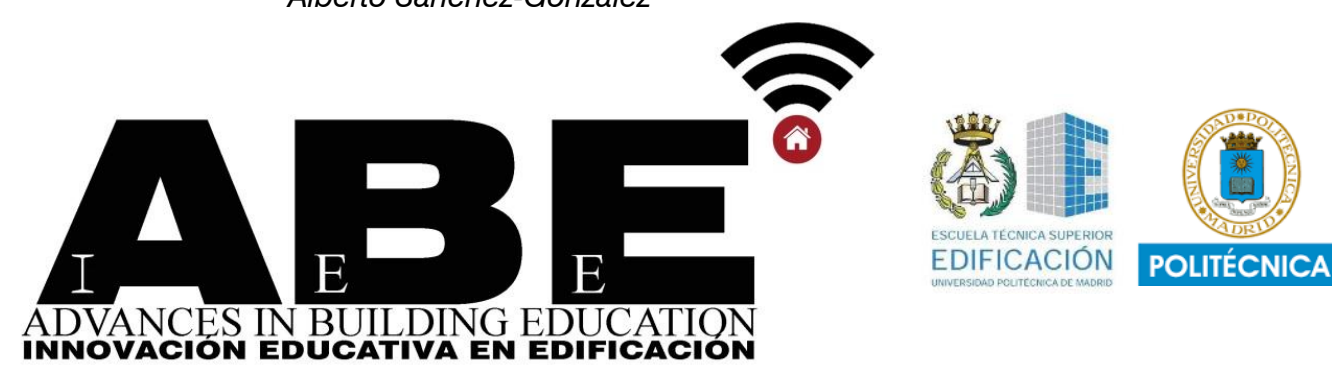

\title{
Peer assessment between students of "energy in buildings" to enhance learning and collaboration
}

\author{
Alberto Sánchez-González ${ }^{1}$ \\ ${ }^{1}$ Department of Thermal and Fluid Engineering, Universidad Carlos III de Madrid e-mail: asgonzal@ing.uc3m.es
}

Recibido: 10/01/2021 | Aceptado: 15/02/2021 | Fecha de publicación: 15/04/2021

DOI: $10.20868 / a b e .2021 .1 .4567$

\section{ABSTRACT}

In educational settings, peer assessment is defined as the process of considering the level, value, worth, quality or success of the outcomes of learning by classmates with the same status (i.e. peers). In the framework of an educational innovation project at Universidad Carlos III de Madrid (UC3M), peer assessment has been implemented during two years in the course of "Energy in Buildings. In this subject, students individually develop their own project, mainly based on software tools, and apply the knowledge and skills learned within the course. The goal of peer assessment in this course is, not so much to increase student's marks, but to increase their learning outcomes. The resulting classroom setting also allows a smoother transition to real-life professional settings and the development of interpersonal skills with future co-workers.

A learning management system was utilized: Aula Global, virtual platform for students at UC3M, that is based on Moodle. Peer assessment was enabled by using the workshop activity in Moodle platform. To guide the assessment by the students, rubric templates were generated in the same virtual platform. This paper presents the lessons learned during the last year of application of peer assessment in "Energy in Buildings" course.

Keywords: Project-based assessment, Workshop, Moodle platform, Rubric. 


\section{INTRODUCCIÓN}

In educational settings, peer assessment is defined as the process of considering the level, value, worth, quality or success of the outcomes of learning by classmates with the same status (peers) [1]. Peer assessment as a teaching system has been recently implemented in courses of buildings [2] and engineering [3].

In the framework of an educational innovation project at Universidad Carlos III de Madrid (UC3M), peer assessment has been implemented during two years in the course of "Energy in Buildings" (EiB) [4]. In this subject, elective of 4rd year in the Bachelor of Energy Engineering, students individually develop their own project, mainly based on software tools. Throughout the development of the project, the students apply the knowledge and skills learned within the course. The individual project accounts for the whole mark in this subject, as long as full continuous assessment is enforced.

The goal of peer assessment in this course is, not so much to increase student's marks, but to increase their learning outcomes. Peer assessment enhances collaboration and critical thinking skills. The resulting classroom setting also allows a smoother transition to real-life professional settings and the development of interpersonal skills with future co-workers.

For peer-review implementation in the class, a learning management system has been utilized. Aula Global, virtual platform for students at UC3M, is based on Moodle. For this purpose, workshop activities in Moodle [5] has been set. To guide the assessment by the students, rubric templates has been generated in the same virtual platform.

This paper presents the lessons learned during the two years of application of peer assessment in "Energy in Buildings" course. Specifically, the results of the last year of application, course 2019-2020, are herein exposed.

The manuscript is structured as follows. The following section states the context of "Energy in Buildings" course, which helps to understand the selected peer review process as explained in Section 3. Before ending with the conclusions, Section 4 summarizes the results obtained in terms of students' project improvements, as well as students' feedback from a survey.

\section{CONTEXT OF THE COURSE}

Energy in Buildings (EiB) is an elective course (6 ECTS) of 4rd year in the Bachelor of Energy Engineering at UC3M, which every year admits 40 new students. Instead of the electives of $4 \mathrm{rd}$ year, the students can enroll in Professional Internship (18 ECTS), which is the preferred option by the students in this Bachelor. Therefore, the number of UC3M students enrolled in "Energy in Buildings" course is quite low.

This subject is taught in English, which attracts the attention of a substantial number of international undergrad students coming to UC3M within Erasmus + and Non-European Mobility (NEM) programs. As a result, the number of international students enrolled in the subject is larger than that of home students (UC3M). Figure 1 depicts for each year, from the beginning of this subject in 2017 , the number of students depending on their origin. The largest number of students enrolled in the course up to date took place on 2019 with 16 students, 12 of which were international, being USA the most present country of origin with 5 students.

The international environment along with the reduced number of students (between 9 and 16 
each year) represent the two main characteristics of the student body in "Energy in Buildings" course. However, despite of the reduced size of the groups, some lack of collaborative learning between the students has been frequently identified by the faculty in this subject.

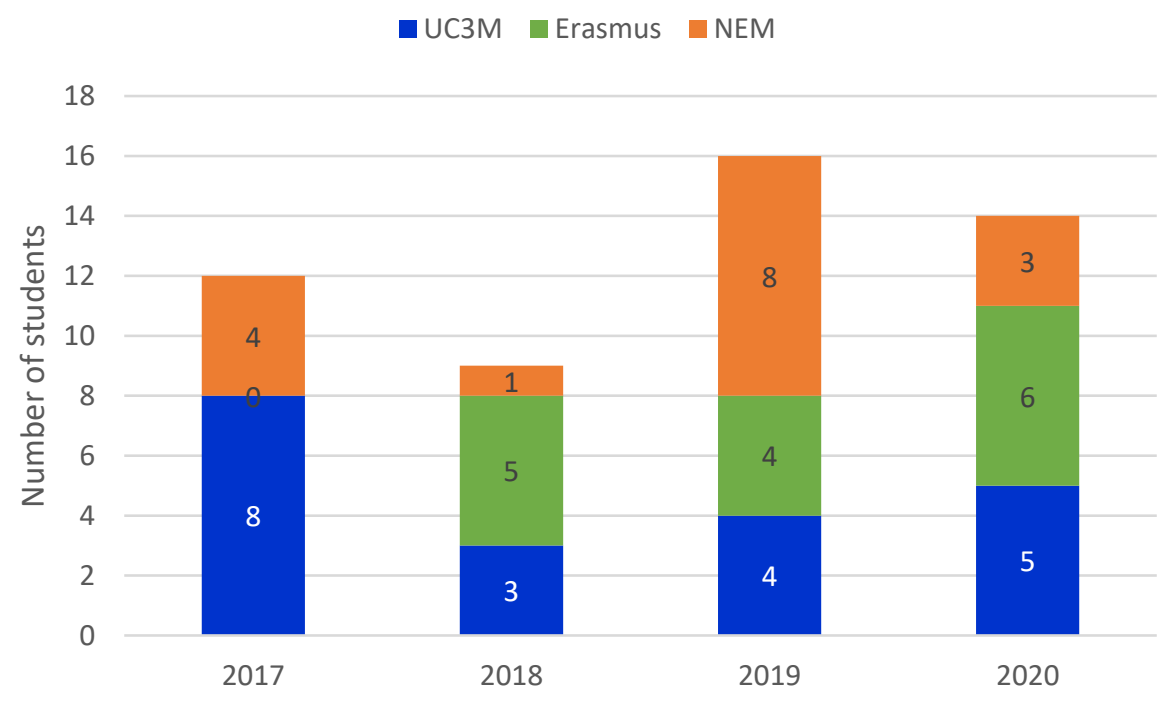

Figure 1: Students of Energy in Buildings each year.

The contents of "Energy in Buildings" [4] are briefly summarized in Table 1 . This course deals with the calculation of energy demands, consumptions and loads in buildings, as well as the sizing of HVAC, lighting and renewable energy systems. Therefore, this is a very applied course, where the learning and use of suitable software tools becomes one of the major goals.

Table 1: Programme of Energy in Buildings

\begin{tabular}{|l|l|}
\hline Contents & Software tools \\
\hline 1. Energy consumption in buildings & HULC, eQUEST \\
\hline 2. Heating and cooling loads & CarrierHAP, MSExcel \\
\hline 3. Refrigeration and heat generation & \\
\hline 4. HVAC systems & CarrierHAP \\
\hline 5. Lighting systems & DIALux \\
\hline 6. Photovoltaic systems & PVSyst \\
\hline 7. Power factor correction & \\
\hline
\end{tabular}

The grading system of "Energy in Buildings" is $100 \%$ continuous assessment. Throughout the course, students individually develop their own personal project, where the knowledge and skills learned within the course are applied, usually with the help of a software tool as pointed out in previous Table 1.
The individual project accounts for the whole mark in this subject. Partial hand-ins (HIs) are spread along the semester to help the follow up process by faculty. Accordingly, six partial handins are scheduled, along with a final oral presentation at the end. The scope of the assignment corresponding to each $\mathrm{HI}$ is listed in Table 2. 
A building type, geometry and location is assigned to each student for the development of the project. For the building use, an educational middle school has been considered up to date, but different building layouts are provided so that each project is particular of the student.

Table 1: Scheduled assignments.

\begin{tabular}{|c|l|}
\hline Hand-in & \multicolumn{1}{|c|}{ Scope } \\
\hline 1 & Energy demand and compliance with standard \\
\hline 2 & Heating and cooling loads \\
\hline 3 & Sizing of HVAC systems \\
\hline 4 & Lighting systems \\
\hline 5 & Sizing of PV system \\
\hline 6 & Power factor correction \\
\hline Final & Oral presentation, encompassing the whole project \\
\hline
\end{tabular}

Given the diverse origin of students and the language of communication, when dealing with building regulations and standards, two options are offered to the students. ASHRAE standards, mainly standard 90.1 [6], are offered to international students, while the Código Técnico de la Edificación (CTE) [7] is enforced to UC3M national students. Some Erasmus+ students, mainly from France or Italy, preferred to follow the Spanish CTE as long as their national standards are similar, since being all of them under the umbrella of the European Energy Performance of Buildings Directive (EPBD) [8]. These students find that the knowledge of
Spanish regulations and software (HULC) is more profitable and can benefit their future professional career.

The location of the case study building is restricted to one or another depending on the building energy standard selected by the student. Respectively, New York City and Madrid are the building locations for ASHRAE and CTE standard. These locations are in the scope of application of each standard and their climates are known by the students. By selecting a specific location, students' results in terms of building energy demand, can be compared.

Table 2: Building location required for each standard.

\begin{tabular}{|c|l|}
\hline Building standard & \multicolumn{1}{c|}{ Location } \\
\hline ASHRAE Standard 90.1 & New York City \\
\hline CTE-HE & Madrid \\
\hline
\end{tabular}

Considering the specific context of "Energy in Buildings", this subject offers appropriate conditions to implement an innovative educational approach. Provided the international environment and the reduced size of the group, the results of innovative approaches can be easily monitored by the professor.
Peer assessment between the students has been implemented during the last two years of teaching of "Energy in Buildings". This approach was supported by UC3M in the framework of an educational innovation project. The original goals of this project were to: (1) implement the use of Workshop activity in UC3M's virtual platform, (2) increase the interaction and collaboration between national and international 
students, and (3) include the peer-review in the grading system of EiB course.

Therefore, the goal of peer assessment in this course is, not so much to increase student's marks, but to increase their learning outcomes. This way, collaboration and critical thinking skills are expected to be enhanced. The resulting classroom setting also allows a smoother transition to real-life professional settings and the development of interpersonal skills with future co-workers.

In the following are explained the implementation of the peer-review process in EiB course, as well as the results yielded in the last year of application.
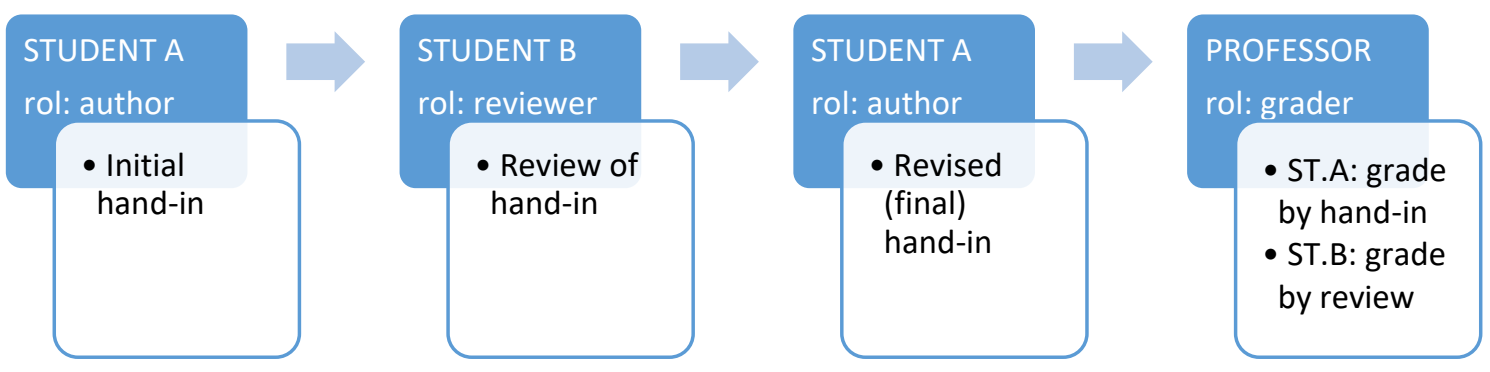

Figure 2: Peer-review process between students

The implementation of PR in "Energy in Buildings" was specifically introduced in the assignments related to the thermal part of the subject. In the first year of implementation, PR was included in the first two hand-ins of the course (Table 2), being kind of pre-hand-ins that

\section{PEER-REVIEW PROCESS}

The peer-review (PR) applied in "Energy in Buildings" follows the sequential process shown in Figure 2. The preliminary hand-in by the students (1st step) is reviewed by their classmates (2nd step), so that a revised and improved final version of the hand-in is finally delivered to the professor (3rd step). Peer assessment does not replace grading by the professor which is performed in the 4rd, and last, step. were revised in the final hand-ins. Because of the time periods needed for the students to assess their peers (a couple of days) and to modify the original hand-in (a week), this procedure was shown unfeasible within the temporal planning of the course. 
Table 3: Mark weights of the assignments and relation with peer assessment.

\begin{tabular}{|c|l|r|}
\hline $\begin{array}{c}\text { Hand-in } \\
(\mathbf{H I})\end{array}$ & \multicolumn{1}{|c|}{ Type } & $\begin{array}{c}\text { Mark } \\
\text { weight }\end{array}$ \\
\hline 1 & To peer assessment & $5 \%$ \\
\hline 2 & Includes revised HI1 & $26 \%$ \\
\hline 3 & - & $14 \%$ \\
\hline 4 & - & $20 \%$ \\
\hline 5 & - & $20 \%$ \\
\hline 6 & - & $5 \%$ \\
\hline Final & Oral presentations & $10 \%$ \\
\hline
\end{tabular}

Consequently, the second year of implementation, the procedure was modified, removing the pre-hand-in way of doing. The first hand-in was fully based on PR and the second hand-in included both the contents of the second assignment and the improved version of the first assignment on the basis of peers (and professor) feedback. As the mark of the first $\mathrm{HI}$ resulted from the PR process, its relative weight was reduced to $5 \%$ so as to limit the impact of possible incorrect reviews (see Table 4). Contrarily, the mark weight of the second $\mathrm{HI}$, fully delivered by the professor, had a great impact on the final grade (24\% of the final mark). As long as HI2 includes the improved version of $\mathrm{HI} 1$, together with the contents of the second assignment, the adopted grading system was considered as appropriate.

In peer assessment activities, students receive two marks: one by the assessment from the peers (reviewers), and another one by the quality of their reviews (supervised by the professor). In $\mathrm{EiB}$ it was decided that for the $5 \%$ mark corresponding to peer-reviewed hand-in 1, half of it $(2.5 \%)$ arose from peer grades, and the remaining half from the quality of reviews. Each student, acting as reviewer, reviewed (and graded) the reports from two of their classmates.

Table 4: Mark weights of HI1; breakdown.

\begin{tabular}{|l|l|r|}
\hline Student role & \multicolumn{1}{|c|}{ Deliverables } & $\begin{array}{c}\text { Mark weight } \\
\text { within HI1 }\end{array}$ \\
\hline Author & Report of HI1 & $50 \%$ \\
\hline Reviewer & Review of two reports & $50 \%$ \\
\hline
\end{tabular}

To guide the peer assessment, a rubric was generated by the professor. The contents of the rubric, along with the use of virtual platform and allocation of reviews, are explained in the following subsections.

\subsection{Workshop activity in Moodle}

For peer-review implementation in the class, a learning management system (LMS) was utilized: Aula Global, virtual platform for students at UC3M. This virtual platform is based on well- known Moodle LMS; specifically, version 3.5 of Moodle is currently used in Aula Global.

Among the wide range of activities available, Moodle provides one specifically designed for peer assessment purpose. The activity for peerreview in Moodle is named Workshop [5]. By default, Workshop activity was not available in Aula Global, but in the framework of the UC3M's innovation project this activity was turned on by the IT department. 
Workshop activity is structured in five consecutive phases, namely: (1) setup, (2) submission, (3) assessment, (4) grading, and (5) closing. The professor controls the switch from one phase to the next, so that the tasks that can be performed by the students are restricted to those available under the active phase at any given time. The so-called Workshop planner tool looks like the image in Figure 3.

In its initial phase, Setup, the professor can adjust the workshop settings, for instance: name of the workshop, instructions for submission and assessment. In the submission phase, students can submit their works. In the assessment phase, students have access to allocated submissions of their classmates, so that these submissions can be assessed by the students. In the grading evaluation phase, final grades for submission and assessment are calculated. When the Workshop is closed, last phase, students see both grades: submission and assessment.

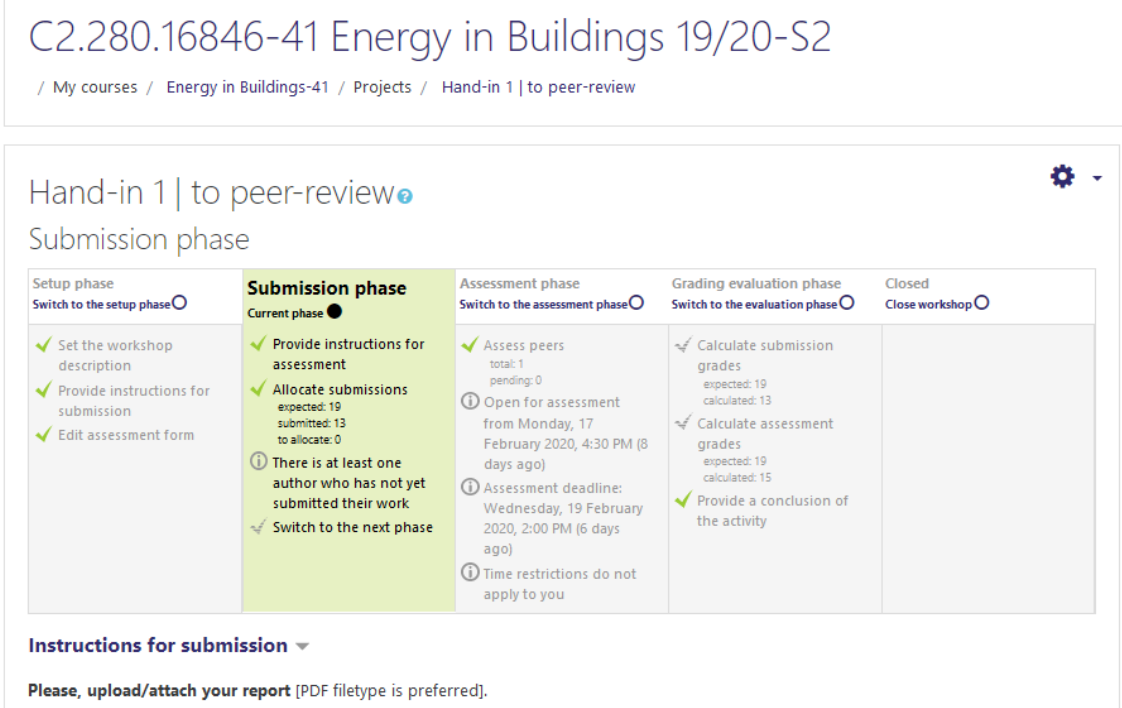

Figure 3: Snapshot of Workshop planner, active on Submission phase.

Full details on the use of Workshop activity in Moodle (version 3.5) are public in their website [9]. Similarly, a description of all the settings available in Moodle's workshop is available online [10].

\subsection{Rubric}

Workshop activity in Moodle allows for 4 different types of grading systems: (1) accumulative grading, which is based on specific aspects; (2) comments, where no numeric grade, but feedback, can be given; (3) number of errors, where yes/no feedback can be given; and (4) rubric, grading is calculated on the basis of responses to specific criteria.

Among the different options available, in EiB the rubric grading system was chosen. With the rubric, by selecting one or another marker (level) within a criterion, a numeric grade (point) is generated. This kind of assessment has the advantage of guiding the student on their reviews, and is not only restricted to yes/no feedback. 
Table 5: Rubric for Hl1.

\begin{tabular}{|c|c|c|c|c|}
\hline $\mathbf{Q}$ & \multicolumn{2}{|l|}{ Question } & Answers & Pts \\
\hline \multirow{3}{*}{1} & \multirow{3}{*}{\multicolumn{2}{|c|}{ On the presentation. Is the report clear, complete and concise? }} & Not at all & 0 \\
\hline & & & $\begin{array}{l}\text { Somehow, but } \\
\text { could be improved }\end{array}$ & 1 \\
\hline & & & Yes & 2 \\
\hline \multirow{2}{*}{2} & \multirow{2}{*}{\multicolumn{2}{|c|}{$\begin{array}{l}\text { Is the climatic zone clearly stated? } \\
\text { (and it's correct according to the corresponding code/standard) }\end{array}$}} & No & 0 \\
\hline & & & Yes & 1 \\
\hline \multirow{2}{*}{3} & \multirow{2}{*}{\multicolumn{2}{|c|}{$\begin{array}{l}\text { Are there figures (charts, graphs) that help understanding the } \\
\text { climate? }\end{array}$}} & No & 0 \\
\hline & & & Yes & 1 \\
\hline \multirow{2}{*}{4} & \multirow{2}{*}{\multicolumn{2}{|c|}{$\begin{array}{l}\text { Is it provided the composition (layers) of the ROOF construction } \\
\text { and its U-factor (thermal transmittance)? }\end{array}$}} & No & 0 \\
\hline & & & Yes & 1 \\
\hline \multirow{2}{*}{5} & \multirow{2}{*}{\multicolumn{2}{|c|}{$\begin{array}{l}\text { If ASHRAE 90.1: Does the ROOF comply with U-factor and R-value } \\
\text { limitations? [be careful with units] } \\
\text { If CTE HE: Is there in the ROOF an insulation layer of thickness } \\
\text { greater than } 2 \mathrm{~cm} \text { ? }\end{array}$}} & No & 0 \\
\hline & & & Yes & 1 \\
\hline \multirow{2}{*}{6} & \multirow{2}{*}{\multicolumn{2}{|c|}{$\begin{array}{l}\text { Is it provided the composition (layers) of the WALL construction } \\
\text { and its U-factor (thermal transmittance)? }\end{array}$}} & No & 0 \\
\hline & & & Yes & 1 \\
\hline \multirow{2}{*}{7} & \multirow{2}{*}{\multicolumn{2}{|c|}{$\begin{array}{l}\text { If ASHRAE 90.1: Does the WALL comply with U-factor and R-value } \\
\text { limitations? } \\
\text { If CTE HE: Is there in the WALL an insulation layer of thickness } \\
\text { greater than } 2 \mathrm{~cm} \text { ? }\end{array}$}} & No & 0 \\
\hline & & & Yes & 1 \\
\hline \multirow{2}{*}{8} & \multirow{2}{*}{\multicolumn{2}{|c|}{$\begin{array}{l}\text { Is it provided the composition (layers) of the GROUND FLOOR } \\
\text { construction and its U-factor (thermal transmittance)? }\end{array}$}} & No & 0 \\
\hline & & & Yes & 1 \\
\hline \multirow{2}{*}{9} & \multirow{2}{*}{\multicolumn{2}{|c|}{$\begin{array}{l}\text { If ASHRAE 90.1: Does the GROUND FLOOR comply with U-factor } \\
\text { and R-value limitations? } \\
\text { If CTE HE: Is there in the GROUND FLOOR an insulation layer of } \\
\text { thickness greater than } 1 \mathrm{~cm} \text { ? }\end{array}$}} & No & 0 \\
\hline & & & Yes & 1 \\
\hline \multirow{2}{*}{10} & \multirow{2}{*}{\multicolumn{2}{|c|}{$\begin{array}{l}\text { Is it provided the composition (glass and frame types) of the } \\
\text { FENESTRATIONS and its U-factor (thermal transmittance)? }\end{array}$}} & No & 0 \\
\hline & & & Yes & 1 \\
\hline \multirow{2}{*}{11} & \multirow{2}{*}{\multicolumn{2}{|c|}{$\begin{array}{l}\text { If ASHRAE 90.1: Do the FENESTRATIONS comply with U-factor } \\
\text { and SHGC limitations? } \\
\text { If CTE HE: Is the U-factor of the FENESTRATIONS less than (or } \\
\text { equal to) } 3.5 \mathrm{~W} / \mathrm{m}^{2} \cdot \mathrm{K} \text { ? }\end{array}$}} & No & 0 \\
\hline & & & Yes & 1 \\
\hline \multirow{3}{*}{12} & \multirow{3}{*}{\multicolumn{2}{|c|}{$\begin{array}{l}\text { Are detailed the design strategies to reduce the heating and } \\
\text { cooling demand? }\end{array}$}} & Not at all & 0 \\
\hline & & & $\begin{array}{l}\text { Somehow, but } \\
\text { could be improved }\end{array}$ & 1 \\
\hline & & & Yes & 2 \\
\hline \multirow{4}{*}{13} & \multirow{4}{*}{$\begin{array}{l}\text { In what range is the total (heating plus } \\
\text { cooling) annual energy demand per } \\
\text { floor surface (D)? }\end{array}$} & \multicolumn{2}{|c|}{ Not provided (or not in $\mathrm{kWh} / \mathrm{m}^{2} \cdot$ year) } & 0 \\
\hline & & \multicolumn{2}{|c|}{$\begin{array}{l}\text { NYC (eQUEST): } D>190 \mathrm{kWh} / \mathrm{m}^{2} \cdot \text { year } \\
\text { Madrid (HULC): } \mathrm{D}>55 \mathrm{kWh} / \mathrm{m}^{2} \cdot \text { year }\end{array}$} & 1 \\
\hline & & \multicolumn{2}{|c|}{$\begin{array}{l}\text { NYC (eQUEST): } 190 \geq \mathrm{D}>160 \mathrm{kWh} / \mathrm{m}^{2} \cdot \text { year } \\
\text { Madrid (HULC): } 55 \geq \mathrm{D}>40 \mathrm{kWh} / \mathrm{m}^{2} \cdot \text { year }\end{array}$} & 2 \\
\hline & & \multicolumn{2}{|c|}{$\begin{array}{l}\text { NYC (eQUEST): } \quad \mathrm{D} \leq 160 \mathrm{kWh} / \mathrm{m} 2 \cdot \text { year } \\
\text { Madrid (HULC): } \mathrm{D} \leq 40 \mathrm{kWh} / \mathrm{m} 2 \cdot \text { year }\end{array}$} & 3 \\
\hline 14 & Overall feedback & Open field for text & & \\
\hline
\end{tabular}

A rubric template was generated in the same virtual platform. The rubric consisted on 13 multiple-choice questions. To allow the students to provide feedback beyond the constrained rubric, an open field text for comments was enabled.

Advances in Building Education / Innovación Educativa en Edificación | ISSN: 2530-7940 | http://polired.upm.es/index.php/abe

| Cod. 2102 | Enero - Abril 2021 | Vol. 5 № 1 | pp. 23/38 | 
Table 5 shows the rubric prepared for the first $\mathrm{HI}$. Most of the questions are Yes/No questions, so that a "Yes" answer leads to 1 point, while "No" leads to no point. Questions \#1 and \#12 have 3 possible answers, leading respectively to 0,1 or 2 points. Finally, question \#13 has 4 possible answers scored in the 0-to-3 range. The open field for overall feedback does not have any points associated. As a result, the maximum points available are 17.

It is important to note that, when defining the rubric in Moodle, no criterion (question) can be left blank, otherwise the answers from the reviewers are not saved. In other words, the number of criteria should be an odd number, as criterion as added in pairs, starting from the three minimum ones available when generating the rubric. In the case herein presented, 13 criteria were defined; the open field text does not apply to such warning.

\subsection{Allocation}

In the assessment phase, submissions are allocated to students for review. Moodle's Workshop allows 3 types of allocation: (1) manual allocation, (2) random allocation, and (3) scheduled allocation, which is actually a random allocation automatically generated when the submission phase is finished.

These two modes of assessment allocation (manual and random) have been implemented for different assignments in EiB. From this experience, each allocation mode has its pros and cons. The random allocation saves time and effort to the professor, but no control over the selection can be made. If the professor is interested in crossing between, a priori, 'good' and 'poor' works, manual allocation is the only way to do it.

Another important aspect in the allocation is the number of submissions to be assessed by each student. Last year of application of the PR in EiB, manual allocation was utilized by assigning 2 reviews per student.

Figure 4 shows the Moodle screen where manual allocation was set; images containing personal data have been blurred for data protection. For each student attending the course ("Participant" in the central column), two students were allocated ("Participant is reviewer of" in the right column); the left column ("Participant is reviewed by") is automatically filled in accordance with previous selection. Self-review is possible, even though has not been used in EiB.

Anonymity is another aspect of PR. By default, Moodle's Workshop considers single blind review, which means that reviewer's identities are hidden to the authors, but reviewers know the identity of the authors. Single blind review is very common in scientific publication process. Single-blind mode was kept in our course. However, as EiB groups are very small, the benefits of blind review in terms of bias avoidance can be argued. 


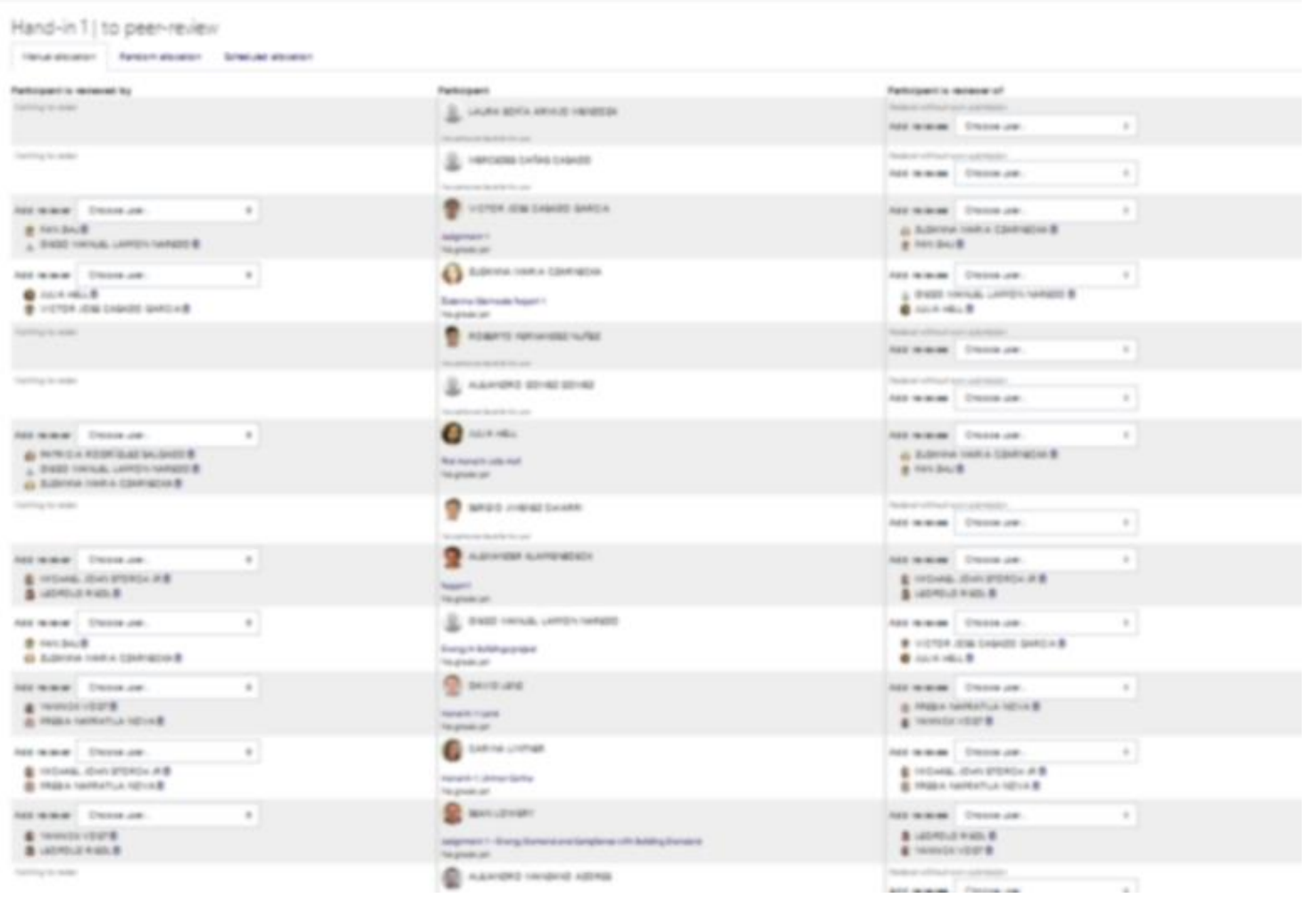

Figure 4: Manual allocation in Moodle (blurred image for protection of personal data).

\subsection{Grading}

From the completion of the rubric, a grade in the range 0 to 10 is automatically generated when each review is finished. As for each hand-in two reviews are delivered, the grade received by the student-authors for their report is the mean of the grades resulting from each review. Ideally, the two marks resulting from the completion of the rubric should be the same (or very similar), as rubric questions are objective.

The final grade from the first hand-in is not only the average one received from the reviewers, but it also considers the quality of the reviews performed by the same student acting as reviewer. As explained before (Table 5), half and half of the grade by $\mathrm{HI} 1$ respectively resulted from assessment and quality of review.
Moodle provides a tool to automatically calculate the grade because of review, which is based on the comparison between marks for the same hand-in. As only two reviews per submission were performed, the tool does not have enough information to estimate a grade by review, and Moodle assigns a 10 mark by default.

Nonetheless, the professor can override the automatic mark generated by Moodle. In EiB, when the difference of grades between reviews for the same report were significant, the professor revised both. If any of them were deficient, the mark by assessment was lowered accordingly in a proportional way.

In the same way, student-reviewers not providing open feedback to the student-authors were penalized with 1 point less in their grade by review. 
Figure 5 shows the grader view in Moodle's workshop activity, showing the grading areas (columns) for submission and assessment. Despite image blurring, original grades marked in red were overridden by the professor into the green ones to their right. Student names in red stand for missing submissions.

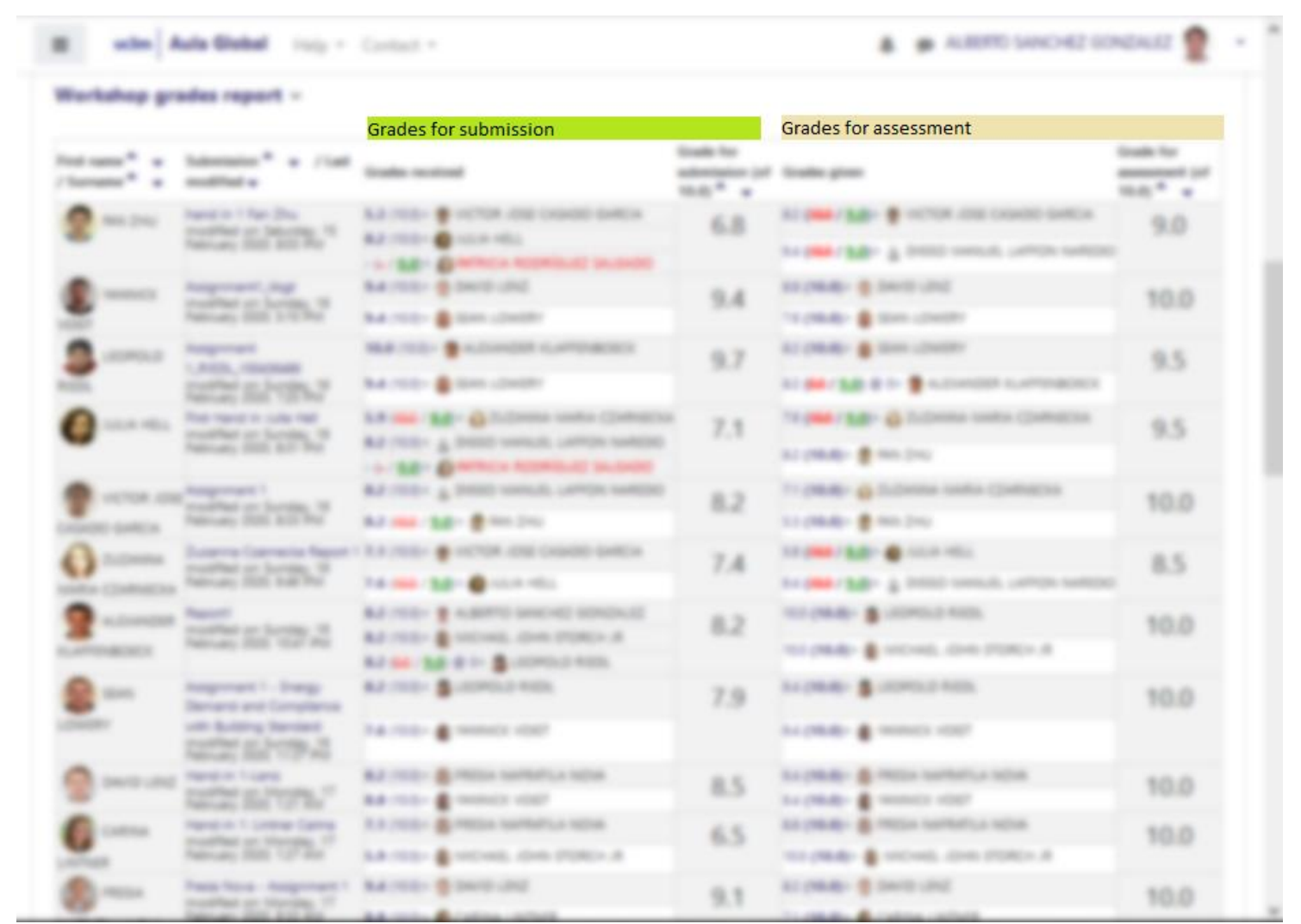

Figure 5: Grader report in Moodle's workshop (blurred image for protection of personal data).

As for the 13 questions/criteria defined in the rubric (Table 6), the average points delivered by the students are depicted in blue in Figure 6; where the maximum points available are denoted by the green columns. Questions 2, 4, 6 and 8 received the maximum punctuation from all the student-reviewers. On the contrary, larger disparity is found in questions from 10 to 13 , despite of being objective too.

Regarding the open field at the end of the rubric, except for two of the students, the remaining ones provided detailed feedback to the student author. This feedback was very appreciated by some of them as shown below. 


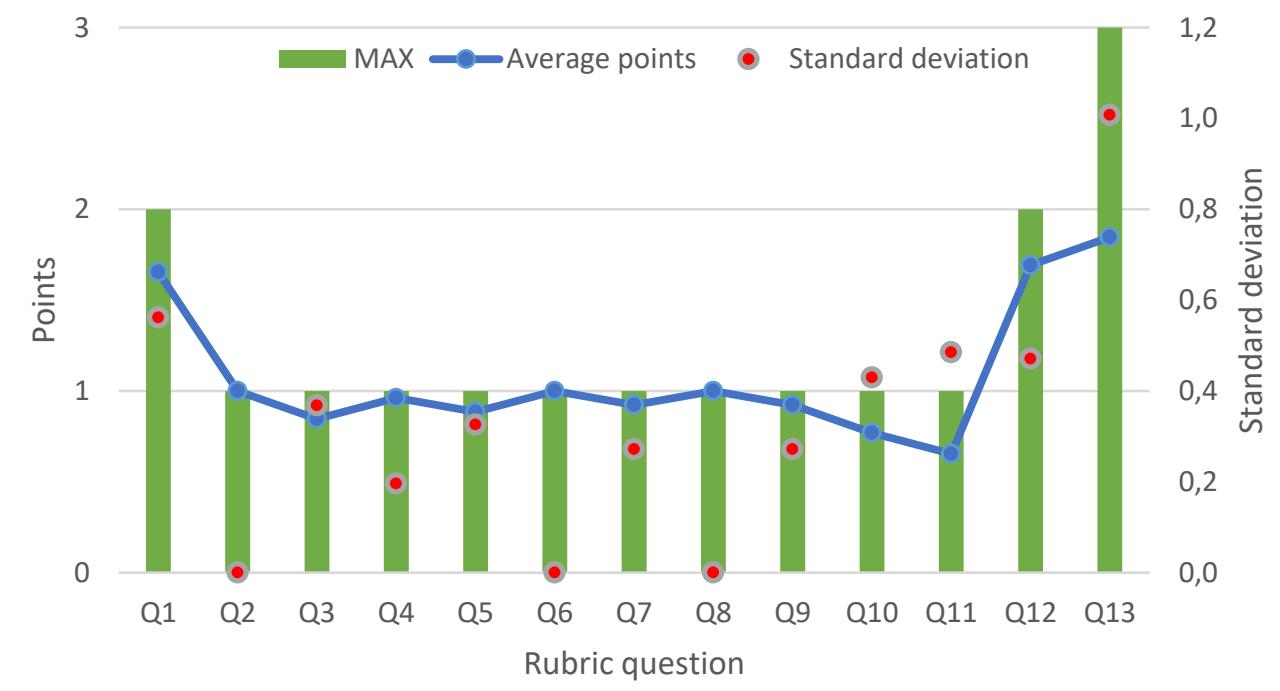

Figure 6: Average grades per rubric question, and standard deviation

\section{RESULTS}

This section exposes the results of the application of peer assessment in EiB course in three ways: comparison of grades between students and professor, improvement of the project output, and analysis of the survey undertaken a posteriori.

\subsection{Comparison of grades}

From the completion of the rubric, high grades resulted from the peer review. For each of the students, anonymized from \#1 to \#13, the orange marker signals the marks received in Figure 7. The same Figure represents in blue the grades given by the professor. Except for student \#7, professor grades are smaller than those resulting from the peer review. Despite being smaller grades, those by the professor generally follow the same trend respect to the PR ones.

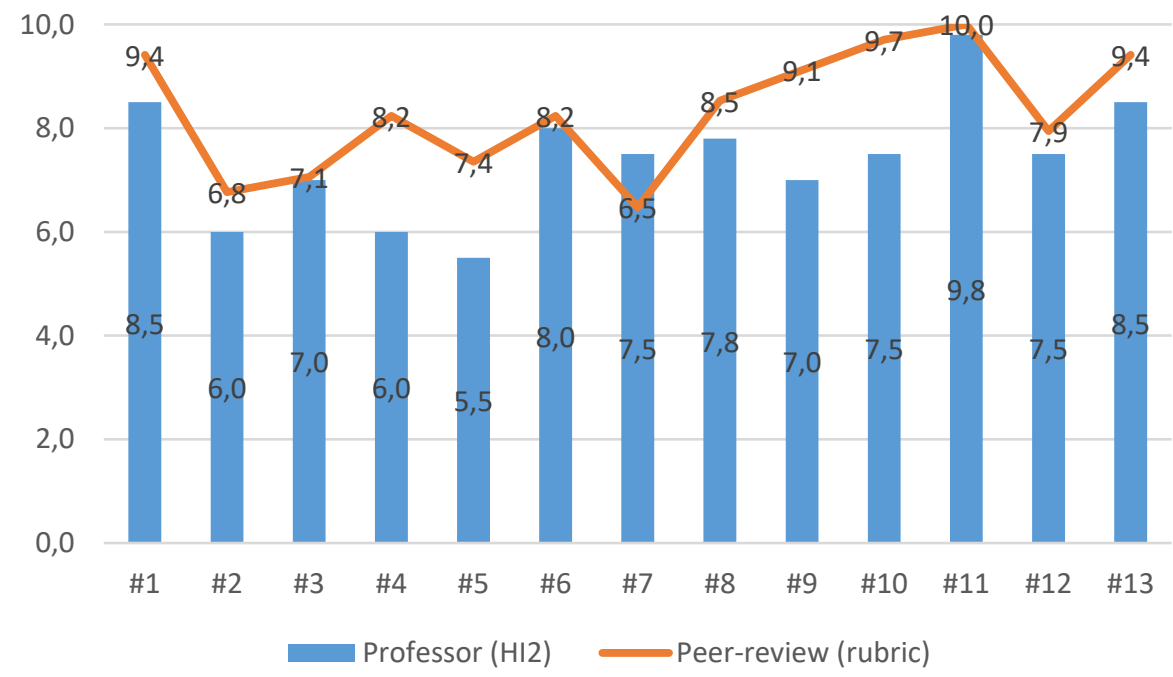

Figure 7: Comparison of grades by the students (PR) and professor (improved version in HI2).

Advances in Building Education / Innovación Educativa en Edificación | ISSN: 2530-7940 | http://polired.upm.es/index.php/abe

| Cod. 2102 | Enero - Abril 2021 | Vol. 5 № 1 | pp. 23/38 | 
It is important to note that the grade provided by the professor, even though based on technical criteria, follows a rather holistic approach that the PR rubric does not allow. For instance, consistency and critical thinking aspects, which are considered by the professor, are hard to be included in a rubric. In any case, the high grades resulting from the rubric are somehow suggesting that rubric criteria could be reformulated.

\subsection{Project improvement}

The original H11, subjected to PR, was improved prior to the final assessment by the professor.
Based on the feedback received from the PR process, the students made modifications on their first assignment and delivered an improved version in HI2.

The annual energy demand by the project building, modeled in HULC (CTE-HE) or EQUEST (ASHRAE 90.1), represents a key indicator of the goodness of the design decisions. Figure 8 shows the simulated annual energy demand obtained by each of the students before (orange) and after (green) the peer assessment.

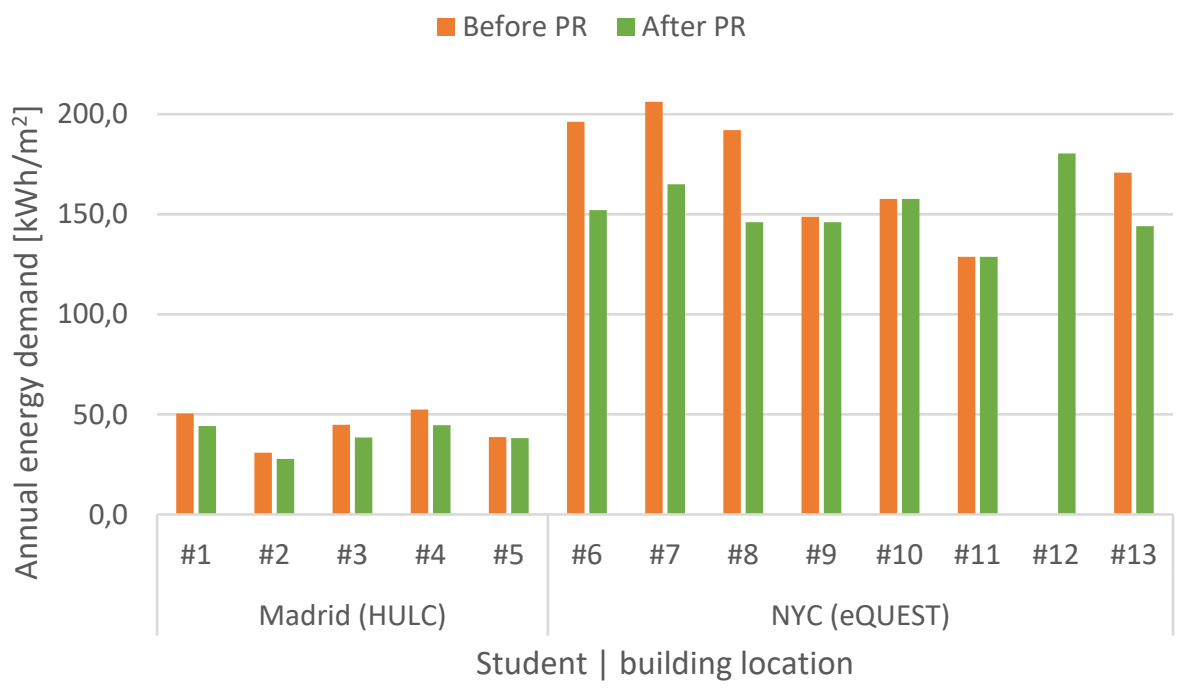

Figure 8: Annual energy demands by the students in the first assignment; before vs. after PR.

In general, most of the students included modifications that helped to reduce the annual energy demand of their building models, as shown in the Figure.

\subsection{Survey}

A survey was requested to the student in order to receive feedback from the peer assessment activity. Table 7 encloses the seven multiplechoice questions included in the survey, which again had an open field for specific comments from the students. 
Table 6: Survey to students; questions and answers.

\begin{tabular}{|c|l|l|}
\hline$\#$ & Question & Answers available \\
\hline 1 & Have you participated before (another subject) in a peer-review? & Yes | No \\
\hline 2 & How useful have you found the feedback received from your peers? & Very | Somewhat | Nothing \\
\hline 3 & How have you found the overall feedback (text) received? & $\begin{array}{l}\text { Motivational | Neutral | } \\
\text { Corrective | None }\end{array}$ \\
\hline 4 & Have you used the received feedback to improve the first hand-in? & $V^{2}$. Somewhat | Nothing \\
\hline 5 & $\begin{array}{l}\text { How much time on average did you required for a single peer-review? (average } \\
\text { of the two assessments) }\end{array}$ & $\left\langle 5^{\prime}\left|5^{\prime}-15^{\prime}\right|>15^{\prime}\right.$ \\
\hline 6 & Do you think that the peer-review is a successful/suitable learning tool? & Very | Somewhat | Nothing \\
\hline 7 & Would you recommend the use of peer-review in the next year of this subject? & Yes | No \\
\hline 8 & Writing field for additional comments/suggestions & \\
\hline
\end{tabular}

As shown in Figure 9, only 5 (out of 13 students) used before a peer assessment activity in another course. As for the feedback received from their peers, barely half of the students found it "very useful", and the other half "somewhat useful". Expect for two students, the rest admitted to use the feedback received to improve their projects. Regarding the kind of feedback received (question \#3), there is a disparity of feelings ( 3 motivational, 3 neutral, and 5 corrective).

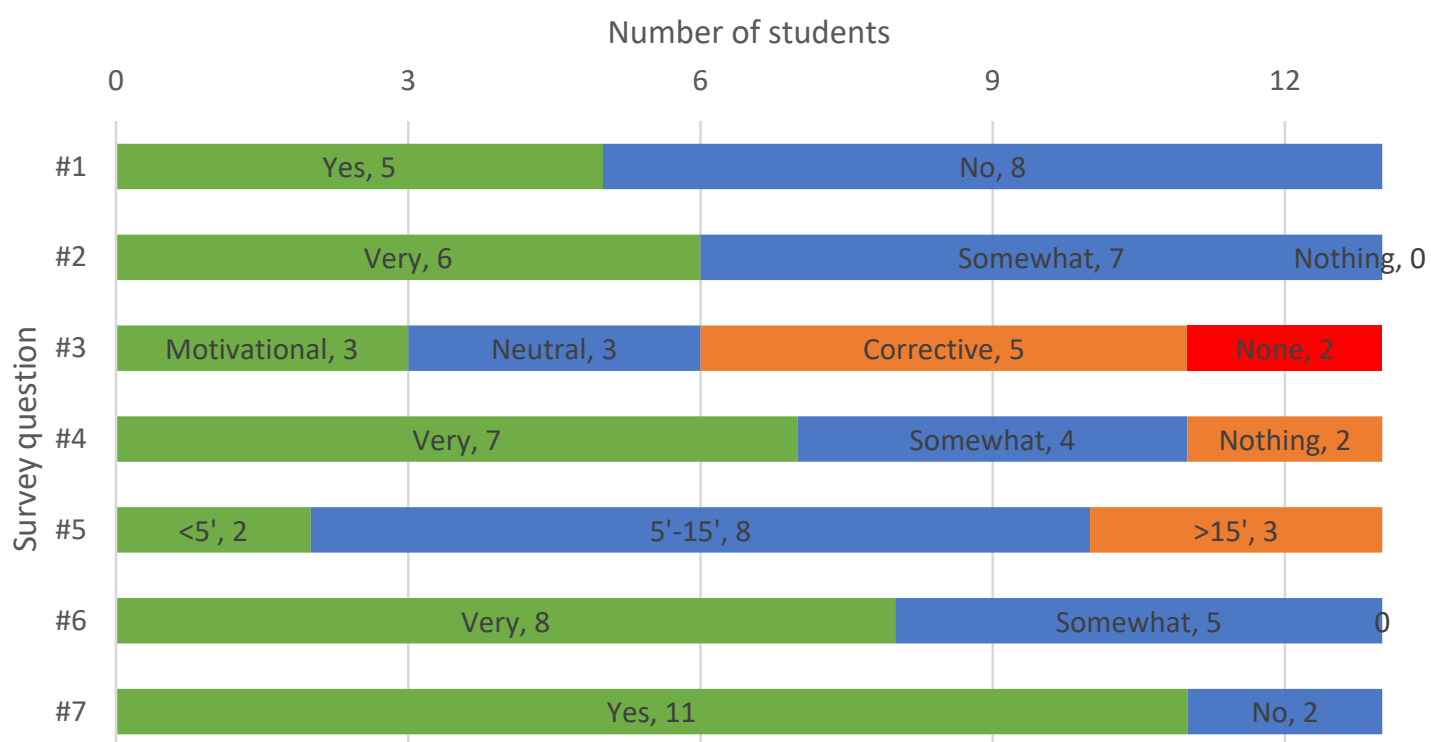

Figure 9: Results of the survey to students (questions stated in Table 6).

In general, the average time required by each student reviewer per review was in the range from 5 to 15 minutes. Two of the students required less than $5^{\prime}$, indeed the two ones that did not provide open feedback. On the other hand, three students required more than 15' to complete the review. $60 \%$ of the students found $\mathrm{PR}$ as a "very" successful learning tool, and the 
remaining $40 \%$ just "somewhat". Again, except two students, the rest recommended the application of PR in the following years of EiB course.

\section{CONCLUSIONS}

Peer assessment represents a feasible learning tool for "Energy in Buildings" course. Because of the reduced size and the international composition of the group, interaction and learning exchange between heterogeneous students have been enhanced by using this peer review activity.

Workshop activity in Moodle platform provides a user-friendly learning system to implement peer assessment. The Workshop planner tool allows the professor to control the different phases of the process: (1) setup, (2) submission, (3) assessment, (4) grading, and (5) closing.

A rubric has been generated to guide the students in the assessment of their peers. The selection of the rubric criteria is key to the final grades resulting from the peer review. In Moodle's Workshop is important to avoid any black criterion so that the student responses to the rubric are conveniently saved.

For each report, two students were manually allocated for reviewing. Despite the fact that the questions in the rubric were objective, the response to some of them varied from reviewer to reviewer. This helped the professor to detect errors in their assessments and correct the corresponding mark.

On the basis of the feedback received from the peer review, the students improved their project and the final version was graded by the professor. By comparing professor and student grades on the same assignment, the former delivered lower marks, which is attributed to: (a) simple questions in the PR rubric, and (b) aspects as consistency and critical analysis that the professor also assesses.

From the survey to the students, $85 \%$ of them admitted taking advantage of the received feedback to improve the project. All of them recognized, to a large $(8 / 13)$ or a medium extent $(5 / 13)$, that peer assessment is a useful tool in the framework of Energy in Building course.

\section{ACKNOWLEDGMENTS}

This work has been developed in the framework of the 16 - Convocatoria de Apoyo a Experiencias de Innovación Docente at Universidad Carlos III de Madrid. The author thanks the students for their participation in the survey, as well as the help by UC3M's Servicio de Informática.

\section{REFERENCES}

[1] K. Topping, "Peer Assessment between Students in Colleges and Universities," Rev. Educ. Res., vol. 68, no. 3, p. 249, 1998.

[2] M. A. Rodríguez Esteban, M. A. FrechillaAlonso, and M. P. Saez-Pérez, "Implementación de la evaluación por pares como herramienta de aprendizaje en grupos numerosos. Experiencia docente entre universidades $=$ Implementation of the evaluation by pairs as a learning tool in large groups. Teaching experience between universities," Adv. Build. Educ., vol. 2, no. 1, p. 66, Apr. 2018.

[3] R. M. Crespo-García and J. Villena-Román, "Revisión entre pares como instrumento de aprendizaje: Una experiencia práctica, Serie de Innovación Docente No. 05-03-01-2005," 2005.

[4] UC3M, “'Energy in Buildings' course program," 2020. [Online]. Available: https://aplicaciones.uc3m.es/cpa/generaFicha? est $=280$ \&asig $=16846$ \&idioma $=2$. 
[5] Moodle, "Workshop activity," Documentation (version 3.5). [Online]. Available: https://docs.moodle.org/35/en/Workshop_activit y.

[6] ASHRAE, "Standard 90.1 Energy standard for buildings except low rise residential buildings."

[7] "Código Técnico de la Edificación. Documento Básico HE (Ahorro de energía)," 2013.

[8] EU, "Energy Performance of Buildings Directive (EPBD)."

[9] Moodle, "Using Workshop," Documentation (version 3.5). [Online]. Available: https://docs.moodle.org/35/en/Using_Worksho p.

[10] Moodle, "Workshop settings," Documentation (version 3.5). [Online]. Available: https://docs.moodle.org/35/en/Workshop_settin gs. 